Discussion Paper No. 01-52

\title{
EU Enlargement and Environmental Policy
}

Andreas Löschel and Marian Mraz

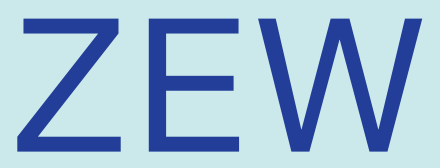

Zentrum für Europäische Wirtschaftsforschung GmbH

Centre for European Economic Research 



\section{Non-technical summary}

The Eastern European Associates have committed themselves to reduce their emissions of greenhouse gases in 2010 according to their targets set in the Kyoto Protocol. Furthermore since 1993 trade liberalization has taken place between all associated countries and the EU as agreed in the Europe Agreements. There is meanwhile a bulk of literature providing quantitative evidence on the economic effects of the full integration of the Central and East European Countries into the EU (Francois 1997, Baldwin, Francois and Portes 1997) as well as the Kyoto Protocol (Weyant 1999 and IPCC 2001). However, there is a lack of quantitative research on the linkage of trade and the environment in the context of the EU enlargement. As a burden from the previous system the CEE countries inherited a significantly damaged environment. The cheap and subsidized energy, lack of market pricing and weak budget constraints distorted the efficient allocation of the available resources and led to overuse and excessive pollution (Klarer and Moldan 1997). In addition to the implementation of other international environmental treaties (e.g. Kyoto Protocol, Sulfur protocol), a pre-condition for the EU membership for the CEEC is the adoption and implementation of the EU environmental acquis. This might become a considerable burden for several countries, when others than the cost-efficient ways will be followed. The following questions arise: "What are the common repercussions of the trade and environmental policies?" "Is it justified to search for a certain combination of both measures, in order to exploit the advantages of each one?" The theoretical literature on the linkage between trade and environment points out especially the spillover effects of the countries' environmental policy action. These studies deal mainly with the impacts of abatement policies on industrial competitiveness and carbon leakage i.e. the reallocation of industries. The international spillovers are mainly transmitted through changes in the terms of trade. The adoption of mitigation policies directly increases the costs of energy consuming industries and might cause a reduction of international competitiveness and thus might negatively affect the energy intensive industries. Unilateral abatement action then may result in a movement of carbon emissions to non-abating countries. This so-called "carbon leakage effect" raises serious doubts on the environmental effectiveness of unilateral action.

For our analysis of the interactions of different environmental policies under the Kyoto Protocol and trade liberalization between the EU and the CEECs in the process of the EU eastern enlargement we use a comparative static multi-sectoral, multi-regional 
computational general equilibrium model (CGE). In the analysis we combine three different environmental policy scenarios with and without trade liberalization between EU and CEEC. In the first scenario we consider only the domestic measures taken by ANNEX-B countries in order to fulfil their commitments. In the second scenario the ANNEX-B countries are allowed to trade with their carbon allowances. In the last scenario all regions are allowed to participate in carbon emission trading. In the trade liberalization scenario we consider only tariffs as the most common trade barriers on imported and exported goods. Trade liberalization is then modelled as an abolishment of the existing tariffs between EU and CEEC. The trading conditions with other regions remain unchanged. We compute the effective carbon reduction requirements, which differ considerably from the agreed targets in 1990 as carbon emissions change until 2010. The analysis shows, that the carbon abatement policies have a direct impact on the overall comparative advantage and the international competitiveness of industries. The strict domestic abatement policy implies the loss of competitiveness in the EU energy intensive industry with negative implications on production and employment. Accordingly energy intensive production increases in CEEC. The computed carbon leakage rates comply with those found in the literature. They are reduced by the introduction of carbon emission trading. As expected, emission trading provides substantial benefits mainly to the main seller of permits i.e. the former Soviet Union and the Central and Eastern European Associates. Those regions also benefit from further trade liberalization. The trade liberalization itself provides large gains for EEAs while it holds only modest gains for EU member states. It does not show a significant impact on carbon abatement policies, however it mitigates welfare losses caused by environmental policies. 
Discussion Paper No. 01-52

\title{
EU Enlargement and Environmental Policy
}

\author{
Andreas Löschel and Marian Mraz
}

Download this ZEW Discussion Papers from our ftp server:

ftp://ftp.zew.de/pub/zew-docs/dp/dp0152.pdf

Die Discussion Papers dienen einer möglichst schnellen Verbreitung von neueren Forschungsarbeiten des ZEW. Die Beiträge liegen in alleiniger Verantwortung der Autoren und stellen nicht notwendigerweise die Meinung des ZEW dar.

Discussion Papers are intended to make results of ZEW research promptly available to other economists in order to encourage discussion and suggestions for revisions. The authors are solely responsible for the contents which do not necessarily represent the opinion of the ZEW. 



\title{
EU Enlargement and Environmental Policy"
}

\author{
Andreas Löschel ${ }^{a, b}$ and Marian Mraz ${ }^{b}$ \\ ${ }^{a}$ Centre for European Economic Research (ZEW) \\ P.O. Box 103443 \\ D-68034 Mannheim, Germany \\ ${ }^{\mathrm{b}}$ University of Mannheim
}

LS Conrad, A5, 68131 Mannheim, Germany

e-mail: loeschel@zew.de,mraz@rumms.uni-mannheim.de

\begin{abstract}
:
The Eastern European Associates (EEA) have committed to reduce greenhouse gas emissions according to their targets set in the Kyoto Protocol. Furthermore since 1993 trade liberalization has taken place between all associated countries and the EU. There is meanwhile a large quantitative literature on the economic effects of full integration of the associated countries into the EU as well as on the Kyoto Protocol. However, there is a lack of quantitative research on the linkage of trade and the environment in the context of the EU enlargement. In this paper we analyze the interactions of different environmental policies under the Kyoto Protocol and trade liberalization in the process of eastern enlargement using a computable general equilibrium model. We find that trade liberalization provides large gains for EEAs while it holds only modest gains for EU member states. Integration does not show a significant impact on carbon abatement policies, but mitigates associated welfare losses.
\end{abstract}

JEL classification: D58, F15, F18, P20, Q25

Keywords: EU enlargement, Kyoto Protocol, computable general equilibrium modeling

\footnotetext{
Acknowledgement: Financial support from the European Commission under the project Climate Change Policy and Global Trade (CCGT) is gratefully acknowledged.
} 


\section{Introduction}

The process of enlargement of the European Union to the associated Central and Eastern European Countries (CEEC) was launched in 1998. ${ }^{1}$ The growing literature on the economic implications of this process deals mainly with the effects of trade liberalization, which has been taking place between the EU and the transition countries as agreed in the Europe Agreements since 1993 along with world trade liberalization following the Uruguay round of the GATT agreement (Baldwin, Francois and Portes 1997, Keuschnigg and Kohler 1999, Keuschnigg, Keuschnigg and Kohler 2000, and Piazolo 2000). The classical trade literature points out mainly the static perfect competition welfare gains from liberalized trade, which stems from the improved allocation of available resources. Relaxing the assumptions of classical trade models and assuming imperfect competition, the existence of unexploited economies of scale allow to consider the pro-competitive effects of trade liberalization (Francois and Roland-Holst 1997), which may lead to even higher welfare improvements. However, the EU enlargement goes much beyond the abolition of trade barriers. The new accession countries are assumed to implement the full range of community policies such as anti-dumping policy, state aid, competition policy and environmental policy. Open questions still remain concerning the participation of the new member states in the EU common agriculture policy (CAP) and the operation of the EU structural funds (see Agenda 2000, EC 1997 and Europäische Kommission 2000).

In spite of the geographical vicinity, the state of the environment in the accession countries differs significantly from the EU. The environmental policy in the EU, which consists of a series of standards and directives, has been developed during a long period of time mainly as a response to the fast economic growth. In contrast, the environmental burden in the new accession countries with lower population density and less intensive land use, but higher demand for energy per unit of production did not appear to be a real constraint on production activities until the beginning of the 1990s. Cheap and subsidized energy, no market pricing and weak budget constraints distorted the efficient allocation of the available resources and led to overuse and excessive pollution (Klarer and Moldan 1997). The transition countries have committed themselves to reduce their emissions of greenhouse gases according to their targets set in the Kyoto Protocol (UNFCCC 1997). Thus they do not only

\footnotetext{
${ }^{1}$ CEECs are the Czech Republic, Hungary, Poland, Estonia, Slovenia, Romania, Bulgaria, Latvia, Lithuania, and the Slovak Republic. While accession negotiations are presently taking place with the first five countries, membership of the last five countries will be postponed to some later stage (Europäische Kommission 2000).
} 
have to implement the whole body of EU directives but to develop their own environmental policy strategies for compliance with this international agreement.

There is meanwhile a bulk of literature providing quantitative evidence on the economic effects of the full integration of the Central and East European Countries into the EU (Francois 1998, Baldwin, Francois and Portes 1997) as well as the Kyoto Protocol (Weyant 1999, IPCC 2001). However, there is a lack of quantitative research on the linkage of trade and the environment in the context of the EU enlargement. In this paper we analyze the interactions of different environmental policies under the Kyoto Protocol and trade liberalization between the EU and the CEECs using a comparative static multi-sectoral, multiregional computational general equilibrium model (CGE). We find that the trade liberalization in terms of abolishment of tariff barriers provides large gains for the CEECs while integration holds only modest efficiency gains for the EU member states. It does not show a significant impact on carbon abatement policies, however it mitigates welfare losses caused by environmental policies. The set up of our paper is as follows. Firstly, we briefly introduce the most important environmental policy issues in the transition countries and the impacts of the environmental policies on the pattern of trade. Secondly, we give an overview of the course of trade liberalization, its presumed economic effects and the impacts on the environment. Thirdly, we outline a CGE Model, which was constructed for the analysis of economicenvironmental questions. Fourthly, we present and discuss the results of several scenarios concerning trade and environmental policies in the context of the EU enlargement and the Kyoto protocol. In the last section we conclude and point out some lines for future research.

\section{The state of the environment and environmental policy in Central and Eastern Europe Countries}

The real state of the environment in transition countries after 40 years of socialism has become subject of increasing concern. In spite of different natural and climatic conditions the transition countries have similar environmental problems, in particular high air, water and soil pollution. Air pollution is mainly due to $\mathrm{SO}_{2}, \mathrm{NO}_{x}, \mathrm{CO}$ emissions and dust particles, caused by the combustion of the low-quality coal in power plants and heavy industry (chemistry and metallurgy). The deposit of $\mathrm{SO}_{2}, \mathrm{CH}_{4}$ and $\mathrm{N}_{2} \mathrm{O}$ has led to higher acidification of the soils, has contributed to the decrease of soil fertility and ultimately has prevented the growth of new forests (e.g. the sulfur triangle). The used agricultural methods led to soil erosion and loss of 
soil fertility. Deposits of nitrogen and phosphorus compounds, pesticides and organic substances have heavily polluted the surface and under water supplies. It is estimated that about 10 per cent of the whole surface of the CEEC has bad water quality. About $50 \%$ of the population in the CEECs used to live in these areas, which belonged to the most polluted areas in the world. Birth problems, learning difficulties, respiratory diseases and short life expectations (e.g. 5 to 7 years shorter in the former Czechoslovakia than in Western Europe) were the noticeable results.

The transition countries and the former Soviet Union used to belong to the 15 biggest global $\mathrm{CO}_{2}$ polluters in the world. Their emissions increased continuously from $800 \mathrm{Mt} \mathrm{CO}_{2}$ in 1950 to $4.800 \mathrm{Mt}$ in 1988 . Thereafter the carbon emissions intensity gradual decreased from $537 \mathrm{t} \mathrm{CO}_{2}$ per million USD of GDP in 1990 to 453 in 1996. These numbers still remain high as compared to the EU. The transition countries show high per-capita $\mathrm{CO}_{2}$ emissions: 11 tons per capita in comparison to 8 tons per capital in the EU and a global average of 4 tons per capita in 1992 (Baumert, Petkova and Barbu 1999). Due to the decreased demand of primary energy, mainly following the economic downturn and substitution for fuels with lower carbon content (Table 1), a sharp decrease of $\mathrm{CO}_{2}$ emissions has occurred. The fast reforming countries Czech Republic, Hungary, Poland, Estonia have managed to reduce their energy intensity up to $38 \%$ during the 6 years after the start of the reforms. Combined policies such as controlled increase of fossil fuel, electricity and heat prices with certain degree of restructuring (breaking the state monopolies in the energy generation and mining companies) have been applied. However very complex systems of cross-subsidies are still existing (Lubinski 1996, Sejak 1996). Nonetheless, some energy projections suggest that the CEEC might not be able to sustain their $\mathrm{CO}_{2}$ commitments of the Kyoto Protocol as they expect to surpass the base year levels due to the higher economic growth caused by the integration process (Table 2). 
Table 1 The structure of the demand for energy (in \%)

\begin{tabular}{lrrrrrrrrrr}
\hline & Solid fuels & Liquid fuels & Natural gas & Nuclear & \multicolumn{2}{c}{ Renewables } \\
& & & & & & & & & & \\
& 1990 & 2010 & 1990 & 2010 & 1990 & 2010 & 1990 & 2010 & 19902010 \\
\hline Poland & 74 & 2 & 13 & 18 & 9 & 23 & 0 & 0 & 4 & 7 \\
Hungary & 22 & 6 & 30 & 26 & 31 & 54 & 13 & 12 & 1 & 1 \\
Czech Republic & 61 & 42 & 19 & 21 & 12 & 29 & 7 & 7 & 1 & 2 \\
Slovenia & 27 & 13 & 34 & 39 & 13 & 25 & 23 & 17 & 5 & 8 \\
Baltic countries & 22 & 11 & 42 & 34 & 23 & 32 & 13 & 18 & 4 & 7 \\
Romania, Bul- & & & & & & & & & & \\
garia, Slovakia & 55 & 38 & 22 & 22 & 15 & 30 & 6 & 6 & 3 & 5 \\
Total & 55 & 38 & 22 & 22 & 15 & 30 & 6 & 6 & 3 & 5 \\
\hline
\end{tabular}

* Source: Cofala et al. (1999)

The environmental legislation in CEEC developed since the 1970s, has remained incomplete and non-effective. Legally obligated very stringent standards could not be fulfilled given the available technologies and the lack on the institutions. Therefore, the CEEC face the difficult problem how to address their serious environmental problems in the current period of the liberalization of their economies. The traditional advice from economists is to use economic incentives more extensively (REC 1993, Toman 1994). Learning from the lessons taken during the transformation, the following points seem to be crucial for the environmental policy in CEEC:

- Environmental protection matters.

- The environmental problems in Central and Eastern Europe are far reaching, so the setting of priorities is necessary.

- Economic restructuring is essential. The achievement of significant results in environmental policy protection requires reconstruction of those spheres of the economy, which present the main source of threat to the environment. Sweeping economic reform is a prerequisite of successful environmental protection (Kaderjak and Powell 1997).

- The cost-efficient strategies matter. The attention should be turned to the support of economic incentives. 
Table $2 \quad \mathrm{CO}_{2}$ emissions in the transition countries (in Mton.)*

\begin{tabular}{lrrrrrrr}
\hline Region & 1990 & 1995 & 2000 & 2005 & 2010 & 2015 & 2020 \\
\hline Poland & 340,9 & 330,1 & 330,1 & 339,6 & 348,1 & 358,8 & 374,4 \\
Hungary & 65,8 & 55,3 & 56,3 & 58,7 & 62,8 & 70,2 & 78,1 \\
Czech Republic & 145,0 & 114,6 & 112,8 & 120,9 & 131,3 & 137,1 & 145,1 \\
Slovenia & 12,5 & 13,4 & 13,7 & 14,8 & 16,4 & 17,9 & 19,8 \\
Baltic countries & 89,2 & 41,7 & 40,5 & 42,5 & 45,9 & 49,8 & 57,1 \\
Romania, Bul- & & & & & & & \\
garia, Slovakia & 653,4 & 555,0 & 553,4 & 576,4 & 604,5 & 633,8 & 674,5 \\
Total & 1306,8 & 1110,1 & 1106,8 & 1152,9 & 1209,0 & 1267,6 & 1349,0 \\
\hline
\end{tabular}

* Source: Cofala et al. (1999)

The new accession countries are obliged to adopt the whole body of environmental directives of the EU i.e. the environmental acquis before the accession. However given the current economic recession and weak assertiveness of the institutions, the direct adoption of the standards might show to be inefficient and ineffective. The costs of adoption and fulfillment of the current EU legislature, based mainly on command and control measures, might become prohibitive for some countries. Furthermore, a relatively small space remains for the use of cost-efficient instruments, which would lower the implementation costs of command and control policies through the use of direct incentives. The application of economic instruments in the CEEC (e.g. pollution fees) has been introduced as a tool of environmental policy since the 1970s and 1980s. However their cost and profit implications have become real with the beginning of the economic reforms. Currently the economic instruments are applied mainly for revenue raising. Their incentive effects on polluters remain neglected. Poland, the Czech Republic and Slovakia primarily use pollution permits, fees and non-compliance fees. Such a system generally has two-tiered price levels, where the former applies for the emissions above the level set by the standard and the later is charged for the non-compliance with the standard. Hungary on the other hand uses product charges for damaging goods. The fees are supplemented with a number of fiscal instruments. Only Slovenia has introduced $\mathrm{CO}_{2}$ taxes. Several specifics for the use of economic instruments in CEEC have to be considered: (i) the final implications of revenue raising instruments depend 
on the utilization of the revenues, (ii) enforcement and monitoring are often weak, (iii) fee exemptions are common.

In the following we turn our attention to the fulfillment of the Kyoto targets for the countries with economies in transition. All the new accession countries have agreed to reduce their greenhouse gas emissions in 2010 according to the levels set in the Kyoto protocol. Hungary and Poland took the opportunity of a "certain degree of flexibility" and selected their own base year, in order to achieve the target at the best of their ability (Table 3). The CEEC countries may reap several benefits from coupling the strong domestic action to reduce greenhouse gases (GHG) with the use of the flexible mechanisms in the Kyoto Protocol. The rationale of the Kyoto mechanisms is to achieve given targets by allowing the emission reductions taking place, where they have the lowest possible costs. This could foster technology and financial flows to the CEEC, where lower cost abatement possibilities are still available. Thus combining domestic action and the participation in the flexible mechanisms can bring additional benefits for CEEC such as (i) upgrading technological capacity and improving energy efficiency, (ii) improving air quality and health, and (iii) attracting financial flows by selling the carbon allowances.

Table 3 Kyoto targets (in \%)*

\begin{tabular}{lcc}
\hline Region & Base year & Kyoto target \\
\hline Poland & 1998 & -6 \\
Hungary & $1985-7$ & -6 \\
Czech Republic & 1990 & -8 \\
Slovakia & 1990 & -8 \\
\hline
\end{tabular}

* Source: Baumert, Petkova and Barbu (1999) and own calculations

In the new enlarged EU, several policy options with respect to climate change policy will emerge (see Michaelowa and Betz 2000). The accession countries may enter the EU Bubble and take part in the European burden sharing. This will, however only be possible in the following commitment period, as according to the Kyoto protocol the EU has to stick to its own bubble (Art. 4.4). The other possibility is a common European environmental and energy taxation based on the Communication on environmental taxes and charges in the Single Market (COM 97 / 9) and the Energy tax proposal (COM 97 / 30). An increasing 
number of countries start to use charges or taxes to fulfill their environmental goals. In addition to Slovenia other countries are also considering $\mathrm{CO}_{2}$ taxes. One of the main reasons is the presumed positive effect on the labor market, the double dividend (Goulder 1995).

The environmental policies however have several repercussions on other areas such as international trade flows, capital flows and technology transfers. The environmental policy action of one country is likely to cause spillovers on other countries. The studies of spillover effects deal mainly with the impacts of abatement policies on industrial competitiveness and carbon leakage i.e. the reallocation of industries. In dynamic considerations technology transfers may generate positive spillovers for the non-abating countries (Grubb 2000).

\section{Competitiveness}

International spillovers are mainly transmitted through changes in the terms of trade (TOT). The terms of trade are measured as the ratio of the countries exports to its imports in value terms. Terms of trade impacts imply a secondary benefit or burden of the primary domestic policy. Carbon strategies influence directly the prices of fossil fuels, increase the production costs of energy consuming industries, and reduce the comparative advantage of the industries as they increase the relative costs of producing a good in that particular country. This leads to the reduction of international competitiveness and will negatively affect the energy intensive industries. However, the country may benefit from the improvement of the terms of trade, when the emissions arise from the goods being exported, given that the imperfect substitutability of goods allow to sell those goods for a higher price. In this case, the overall welfare effect depends on the change in the terms of trade relative to the level of abatement costs. Non-abating countries suffer symmetric welfare loses from more expensive imports. However, empirical studies estimate that pollution abatement costs of developing countries are about 1 per cent (and not exceeding 5 per cent) of the production costs (Nordström and Vaughan 1999). They find that energy intensive industries tend to be capital intensive and thus are not very likely to move to capital scarce countries like the transition economies in Eastern Europe.

\section{Carbon leakage}

Unilateral abatement action may result in a movement of carbon emissions into nonabating countries. This raises serious doubts on the environmental effectiveness of unilateral 
action due to the so-called "carbon leakage effect". Carbon leakage is defined as the ratio of the total increase in carbon emissions of the non Annex-B countries to total emissions abatement by Annex-B countries. Following Rutherford (1995) there are three basic channels, through which carbon leakage may occur. Firstly, the carbon leakage may arise when in the abating countries the energy intensive industries lose their competitiveness and production relocates the emissions in non-abating countries. Secondly, the decrease in energy demand in large regions due to carbon mitigation policies induce a drop in the world energy prices, which lead to an increase in demand in the other regions. Thirdly, carbon leakage may be induced through changes in national income due to the changes of terms of trade. Estimates for the carbon leakage rate range from about 5 to 35 per cent (EMF 1999).

\section{Trade liberalization between CEEC and the EU}

According to the decision of the European summit in Copenhagen 1993, the CEEC may enter the EU as soon as they express their concern about the membership and fulfill the conditions known as the Copenhagen criteria. These require the democratic organization of the state justice, the existence of a market economy and the complete adoption of the EU acquis communtaire. The consideration of the economic development of the transition countries as well as its environmental implications represents a major challenge since several features of the transition process have to be kept in mind: (i) the sharp decrease of the domestic production and exports during the beginning of the reform followed by a slow growth, (ii) obsolete production capacities with low capital and labor productivity and energy efficiency, (iii) distorted price systems especially in the energy and agricultural sector due to the remaining subsidies (Klarer and Moldan 1997).

Most of the CEECs have decided to implement a ,shock therapy“ (World Bank 1991 and 1999), the fast economic adjustment to the market. Siebert (1991) considers as main parts of the reform process macroeconomic stabilization, real microeconomic adjustment and creation of institutional frameworks. We focus here on the microeconomic adjustment, especially on the issues concerning the liberalization of trade. The objective of a further extension of the common market in Europe is the expected increase of welfare through the reduction of existing structural imperfections, immersion of efficiency gains through toughened competition and particularly the exploitation of economies of scale. Since 1993 the gradual reduction of tariffs and quantitative trade barriers between the EU and the CEEC has 
been taking place. This is however far from being free trade. The EU has imposed several anti-dumping and price-fixing arrangements, which largely restrict the CEEC exports of particularly "sensitive goods" such as industry products, apparel and agricultural production. The trade liberalization succeeds in an asymmetric way, where the CEEC disposes longer time periods for tariff reductions. This points to the expectation of larger welfare changes on the side of the CEEC after the completion of the trade liberalization. In the following we are considering the effects of trade liberalization between the EU and the new accession countries using a multi-commodity, multi-country trade CGE model. However, full EU membership involves a much deeper integration of commodity and factor markets through the Single Market program (which will reduce real trade cost) and includes in addition the adoption of EU policies in the fields of e.g. anti-dumping, state aids and competition policy, and the participation in the EU common agricultural policy (CAP) and the European structural funds (ESF).

Trade integration holds a clear potential for mutual welfare gains for the incumbent EU countries as well as for the entrants. Since trade liberalization involves larger tariff cuts for the CEECs than for the EU (imports from CEECs amount only to 4 per cent of EU imports, but two-thirds of the CEECs imports are from the EU), initial protection levels suggest that income gains from enlargement are much higher for CEECs than for the EU (Baldwin, Francois and Portes 1997). Following Francois (1997) CGE models are able to capture (i) static allocation effects emphasized by the classical trade theory, (ii) the so-called pro-competitive effects, stemming from the interactions of different market structures and trade policies and (iii) the effects of the accumulation of the human and physical capital.

\section{Static efficiency gains from trade}

Traditional theory emphasizes static welfare effects. The most common trade barriers are taxes on imported and exported goods known as tariffs. The reduction of tariff distortions promises the usual welfare gains. Tariffs tend to shift resources from the export industries to the import competing industries, through the increase of the domestic price of the imported goods. Thus they protect the operations of the home industries with regard to import competition. The EU applies relatively low trade barriers vis-a-vis the rest of the world in comparison to the accession countries, although the protection of agriculture is considerably higher. Well-known perfect competition allocation effects on the sectoral level are trade creation, trade diversion and terms of trade effects. Both trade creation and trade diversion 
result from a fall in the market price as tariffs are abolished. Trade creation implies a lower price of some goods and necessarily leads to higher consumption. On the contrary, trade diversion implies a higher real price of some goods and results in lower consumption. The welfare impacts of the mentioned effects depend on existing substitution possibilities. Assuming that the price elasticities are positive for all goods, both shifts will be accompanied by inter-commodity substitution. Therefore, welfare implications are ambiguous (Lipsey 1960). Under the single market the traded goods (EU imports from the CEEC as well as the CEEC imports from the EU) become duty-free, i.e. the existing trade barriers between those two regions will be abolished. Furthermore the usual trade costs stemming from the existing physical and technical barriers (e.g. border controls, different technical standards) will be far lower. The welfare effects from higher imports from the EU (as well as vice versa) will be captured by the trade creation effect. Its magnitude depends on the size of adjustment costs in the CEEC industries and distributional effects emerging from changes in factor prices. On the other hand, the availability of lower price imports from the new members of the customs union might cause trade diversion from the former supplier to the new member countries (Keuschnigg, Keuschnigg and Kohler 2000).

\section{Pro-competitive effects of trade liberalization}

Perhaps more important then the static allocation effects are the pro-competitive effects of trade liberalization (Francois and Roland-Holst 1997). These are trade effects emerging from the existence of scale economies and imperfect competition. The pressure of increased competition forces firms with market power that set prices $(\mathrm{P})$ above marginal costs (MC) down to competitive pricing. The pro-competitive effects may relate to increased economies of scale, the falling of the production costs (lowering the mark-up) and the increase of product varieties (the expansion of output). This effect is comparable to the gain that could be achieved in a closed economy by eliminating the monopoly distortion. It adds to the usual comparative gains from trade. The pro-competitive (product expansion) effect is decomposed into two effects (Markusen 1995):

$$
\left(p-M C_{x}\right) \Delta X=\left(p-A C_{x}\right) \Delta X-X\left[\frac{\Delta A C_{x}}{\Delta X}\right] \Delta X
$$


The first term on the right hand side is the so-called pure profit effect, arising from the fact that imperfectly competitive firms set prices above average costs. The second term describes the decreasing-average cost effect, which reflects the gains from the fall of average costs of the production as firms expand output. The third source of gains from trade is the firm exit effect that reflects the trade-off between the existence of more firms on the market and the desirable entire industry product due to a downward sloping average cost curve. Free entry drives profits to zero and with the opening of trade some firms will exit due to negative profits. Fewer firms will then produce the same output with lower average costs. In addition, the recent literature emphasizes the increase of varieties (Markusen 1981, Helpman and Krugman 1985).

\section{Accumulation effects}

Cross-country studies show considerable inconsistencies between results from static numerical studies and linkages between trade policies and incomes through investments. The static effects fail to account for the relationship between trade, investment and growth, which is fairly well established empirically. According to classical growth theory the changes in saving and investment patterns provide a potential for accumulation. The accumulation effects capture the changes in the amounts of resources through the interaction between trade policy and capital accumulation (Francois, McDonald and Nordström 1996).

The effects of free trade on the environment occur mainly indirectly through the changes in production and consumption patterns. There are four categories of environmental effects on trade. The scale effects arise from higher growth, which stems from the trade liberalization. The increase in production causes more emissions. Considering the environment as a consumption good, the increased personal income may lead to an increased demand for a wide range of goods e.g. for environmental amenities. This illustrates the environmental benefits from trade. However environmental quality is a public good and thus the rising demand for environmental quality needs to be transformed into more restrictive environmental standards. Finally economic growth is followed by a decline of the population, which is one of the major sources of pressure on natural resources. Product and technology effects capture the change in products varieties that become available after the trade liberalization, as well as the easier access to foreign technologies. The increase of pollution often leads to an over-proportional increase in environmental damage. Thus decentralization might alleviate the damage from pollution through the spatial distribution of production i.e. 
shifting the production to other regions. This is called the spatial effect. Finally, trade liberalization alters the allocation of the resources between the production sectors, the socalled composition effect (Bommer 1998, Nordström and Vaughan 1999).

\section{Description of the CGE Model}

Computable general equilibrium modeling provides a useful and widely used tool for applied policy analysis and is particularly suited to the analysis of tax and trade policy issues. There is a need for such a tool, especially in transition economies, which are currently designing their new economic policies. This section presents the main characteristics of a comparative-static multi-sector computable general equilibrium model of the world economy designed for the medium-run economic analysis of environmental constraints and trade policy (see Appendix for the algebraic model formulation). The analysis covers 7 sectors and 5 regions as described in Table 4. The regional aggregation covers beside the EU-15 (EUR) and the Central European Associates (CEA), that is Bulgaria, Czech Republic, Hungary, Poland, Romania, Slovakia and Slovenia, the most important regions of the Kyoto protocol, i.e. the other Annex-B countries (RAB) taking on legally binding commitments on greenhouse gas emissions, particularly Australia, Canada, Japan, Indonesia and the US, the Former Soviet Union (FSU) as a main supplier of "hot air", and other countries without carbon abatement requirements (ROW) such as Brazil, China, India. The regional aggregation follows the aggregation of the GTAP4 database. However, it should be kept in mind that the costs and benefits of enlargement are unevenly distributed across present EU member countries as well as across different central and eastern European countries depending on the respective trade share that is exposed to potential competition (see Breuss and Schebeck 1999). With respect to environmental policy, the EU has done a reallocation of the EU bubble target among the member states of the bubble in 1998 leading again to a very uneven distribution of emission reduction requirements (Michaelowa and Betz 2000). The sectoral aggregation captures key dimensions in the analysis of greenhouse gas abatement such as differences in carbon intensities and the degree of substitutability across energy goods and carbon-intensive nonenergy goods. The energy goods identified in the model are coal (COL), natural gas (GAS), crude oil (CRU), refined oil products (OIL) and electricity (ELE). The non-energy sectors include important carbon-intensive and energy-intensive industries (EIS), which are potentially most affected by carbon abatement policies and other, non-energy intensive 
sectors (Y). The primary factors in the model include labor (LAB), physical capital (CAP) and fossil-fuel resources (RES). Factor markets are assumed to be perfectly competitive. Labor and physical capital are treated as perfectly mobile across sectors. Fossil-fuel resources are sector-specific. All factors are immobile between regions. However, the single market foresees more integrated factor markets leading eventually to free movements of the production factors within the enlarged single market.

\section{Production}

Within each region, each producing sector is represented by a single-output producing firm which chooses input and output quantities in order to maximize profits. In the model nested constant elasticity of substitution (CES) cost functions are employed to specify the substitution possibilities in domestic production between capital, labor, energy and material (non-energy) intermediate inputs. In non-fossil fuel production (ELE, EIS, OIL, Y) intermediate non-energy goods and crude oil are employed in fixed proportions with an aggregate of energy, capital and labor at the top level. At the second level, a CES function describes the substitution possibilities between labor and the aggregate of capital and the energy composite. At the third level, capital and the energy composite trade off with a constant elasticity of substitution. The energy aggregate is, in turn, a nested CES composite of electricity and primary energy inputs. The primary energy composite is defined as a CES function of coal and a CES aggregate of refined oil and natural gas. Fossil fuel production (COL, CRU and GAS) is a CES composite of a sector-specific fossil-fuel resource and a Leontief aggregate of labor, capital and intermediate inputs. The substitution elasticity between the specific factor and the Leontief composite is calibrated in consistency with exogenously given price elasticities of fossil fuel supplies. 
Table 4 Regions and sectoral aggregation

\begin{tabular}{llll}
\hline Sectors & & Countries & \\
\hline COL & Coal & EUR & EU15 \\
CRU & Crude oil & CEA & Eastern Europe \\
GAS & Natural gas & FSU & Former Soviet Union \\
OIL & Refined oil products & RAB & Rest of Annex B \\
ELE & Electricity & ROW & Rest of the world \\
EIS & Energy intensive sectors & & \\
Y & Other sectors & & \\
\hline
\end{tabular}

\section{Private and government demand}

Private demand for goods and services is derived from utility maximization of a representative household subject to a budget constraint. Total income of the representative household consists of factor income and transfers. In our comparative-static framework, overall investment demand is fixed at the reference level. Utility is derived from consumption. Final demand of the representative agent is given as a CES composite of energy aggregate and non-energy consumption composite. Substitution patterns within the energy aggregate and the non-energy consumption bundle are reflected via Cobb-Douglas functions.

The government distributes transfers and provides a public good (including public investment), which is produced with commodities purchased at market prices. In all simulations, we impose revenue-neutrality in the sense that the level of public provision is fixed. Subject to this equal-yield constraint, additional revenues from environmental taxes get recycled through cuts in labor costs (social insurance payments).

\section{International trade}

All goods are traded in the world markets. Following Armington (1969), foreign trade modeling involves international product differentiation in the sense that imported and domestically produced goods of the same kind are treated as incomplete substitutes. The aggregate amount of each good is divided among imports and domestic production. Intermediate as well as final demands are (nested CES) Armington composites of domestic 
and imported varieties. The assumption of product differentiation permit the model to match bilateral trade with cross-hauling of trade and avoids unrealistically strong specialization effects in response to exogenous changes in trade (tax) policy. Bilateral trade flows are subject to export taxes, tariffs and transportation costs and calibrated to the base year 1995.

\section{Carbon abatement}

GHGs and related gases have direct radiative forcing effects in the atmosphere. The various gases result from industrial production, fossil fuel consumption and household activities. The Kyoto Protocol includes carbon dioxide $\left(\mathrm{CO}_{2}\right)$, methane $\left(\mathrm{CH}_{4}\right)$, nitrous oxide $\left(\mathrm{N}_{2} \mathrm{O}\right)$, hydrofluorocarbons (HFCs), perfluorocarbons (PFCs), and sulphur hexafluoride $\left(\mathrm{SF}_{6}\right)$ as gases subject to control. We do not consider the abatement of a complete basket of GHG emissions from all energy-related sources as in the Kyoto Protocol but focus on carbon dioxide abatement from fossil fuel consumption given that it constitutes the bulk of the contribution to global warming. Carbon emissions are associated with fossil fuel consumption in production, investment, government and private demand. Carbon is treated as a Leontief (fixed coefficient) input into production and consumption activities. Each unit of a fuel emits a known amount of carbon where different fuels have different carbon intensities. The applied carbon coefficients, which are assumed to be constant across regions, are $25 \mathrm{MT}$ carbon per EJ for coal, 14 MT carbon per EJ for gas and 20 MT carbon per EJ for refined oil.

Carbon policies are introduced via an additional constraint that holds carbon emissions to a specified limit. The solution of the model gives a shadow value on carbon associated with this carbon constraint. This dual variable or shadow price can be interpreted as the price of carbon permits in a carbon permit system or as the $\mathrm{CO}_{2}$ tax that would induce the carbon constraint in the model. The shadow value of the carbon constraint equals the marginal cost of reduction. It indicates the incremental cost of reducing carbon at the carbon constraint. The total costs represent the resource cost or dead-weight loss to the economy of imposing carbon constraints. Carbon emission constraints induce substitution of fossil fuels with less expensive energy sources (inter-fuel fuel switching), fuel-non-fuel substitution or employment of less expensive manufacturing and production techniques (energy savings). On the consumption side, higher energy prices imply a change in the consumption mix which results in a loss of welfare (consumer surplus). The only means of abatement are hence interfuel and fuel-non-fuel substitution and a reduction of intermediate and final consumption. 


\section{Parameterization}

Data from two different sources are combined to yield a consistent benchmark data set for 1995. The main data source underlying the model is the GTAP version 4 database that represents global production and trade data for 45 countries and regions, 50 commodities and 5 primary factors (McDougall, Elbehri and Truong 1998). In addition we use OECD/IEA energy statistics (IEA 1996) for 1995. Reconciliation of these data sources yields the benchmark data of our model (see Babiker and Rutherford 1997). For this application the data set has been aggregated as shown in Table 4. The given set of benchmark quantities and prices together with the substitution elasticities given in the Appendix completely specify the benchmark equilibrium.

\section{Interpretation of the results}

The literature provides several available estimates of the costs and benefits of the EU enlargement process using CGE models. Baldwin, Francois and Portes (1997) provide two sets of result. In the so-called "conservative" scenario they capture only the allocation and accumulation effects of the trade liberalization between the EU and CEEC. All the regions seem to gain from it, the CEEC, however, gain much more than the EU in relative terms due to the positive income effects and a reduction of previously higher previous distortions. Furthermore, the improved access to the EU markets leads to a fast increase of CEEC exports. In the less conservative scenario the CEECs are allowed to join the EU. This has clear implications on the decrease of the uncertainty followed by a decrease of the risk premiums. The results are in the same fashion as in the former scenario, however the gains increase due to the risk premium effect.

Keuschnigg and Kohler (1999) and Keuschnigg, Keuschnigg and Kohler (2000) consider the impacts of the EU enlargement on Austria and Germany. In their first scenario they assess a bilateral tariff removal. Their full accession scenario contains all main issues of the EU enlargement process (e.g. trade liberalization, budgetary implications and common agriculture policy). The study concludes, that there are positive welfare benefits for Austria as well as for Germany from the closer integration of commodity markets. The model however captures also the adjustment pressure from the increased import competition and the loss of some of the external protection from the previous trade regime. In addition to this, all the 
members of the enlarged EU will have to face a more expensive Union with a clear fiscal implication.

Piazolo (2000) considers the welfare effects of Poland's integration into the EU. The economic effects of the EU membership contain the overall abolishment of tariff barriers between the EU and Poland and the adoption of common external tariffs. The study includes also the implementation of the single market, which will decrease the real trade costs through the abolition of custom and fiscal controls and the harmonization of standards. The results of the simulations are mainly in line with the two previous models and show an increase in welfare in all scenarios. Other studies focus e.g. on the specifics of the common agriculture policy and fiscal issues (Frandsen and Jensen 2001).

The economic impacts of different trade and environmental policies in the process of the EU enlargement are analyzed in this section. We extend this estimates of the effects of the EU enlargement through the inclusion of alternative environmental policies and run three environmental policy scenarios under two different patterns of trade. We simulate a completely liberalized trade between EU vis-a-vis CEEC, where all trade barriers are set equal to zero. The three different scenarios of environmental policy are distinguished by the different degree of flexibility that is allowed in reaching the Kyoto commitments:

[DOMESTIC] Each country applies only domestic measures (e.g. a carbon tax) to comply with their commitments in the Kyoto Protocol. There is no international trade in carbon permits.

[ANNEX] The Annex-B countries are allowed to trade with their carbon allowances.

[GLOBAL] All regional restrictions on trade with carbon permits are relaxed and all countries may participate in carbon trade.

Those three scenarios are considered within two different patterns of international trade between EU and CEEC, while the trade conditions vis-a-vis third countries remain unchanged:

[NO-LIB] No trade liberalization between EU and CEEC takes place.

[LIB] EU and CEEC liberalize trade vis-a-vis. Tariff trade barriers between EU and CEEC are abolished. 
It is important to notice that the effective reduction requirements for the so-called Annex-B countries that accepted quantified limitations on emissions, the effective reduction rates will considerably differ from their agreed targets in 1990 as carbon emissions change until 2010. Table 5 recounts the effective reduction rates for 2010, following energy projections (DOE 1998). We notice that the effective cutback of the EU is more than twice in 2010 as compared to the agreed commitments. On the other hand FSU and CEA provide disposes of hot air, as their effective commitments will not become binding.

Table 5 Nominal and effective $\mathrm{CO}_{2}$ reduction requirements

\begin{tabular}{lcc}
\hline Region & $\begin{array}{c}\text { Nominal reduction } \\
\text { (in \% wrt 1990) }\end{array}$ & $\begin{array}{c}\text { Effective reduction } \\
\text { (in \% wrt 2010) }\end{array}$ \\
\hline CEA & -7 & 4.2 \\
FSU & 0 & 31.7 \\
RAB & -5.5 & -28 \\
EUR & -7.7 & -16.6 \\
ROW & 0 & 0 \\
\hline
\end{tabular}

DOMESTIC - Domestic abatement policies.

In our first scenario, each country has to fulfill its commitments by its own measures (e.g. a carbon tax or a domestic tradable permit system) without any trading across the regions. The countries use the most efficient economic instruments to reduce their emissions. As those become scarcer, the price of abatement increases. Abatement takes place until the marginal abatement costs equal the carbon tax or the permit price. The results are shown in Table 6.

The zero values of the marginal abatement costs indicate no carbon cut requirements (ROW) or no binding commitments in FSU ("Hot air"). Even with some hot air potential CEA is facing small carbon taxes since energy intensive production is increased, driving carbon emissions above the carbon allowances. High carbon taxes in EUR and RAB in comparison with CEA promises further cost savings from the shift of some abatement to the CEA. The welfare impacts are measured as a percentage change in real consumption with respect to the $\mathrm{BaU}$ scenario thus they do not include environmental benefits. Welfare effects 
of integration are much higher for the CEA than for EUR. This result confirms the calculations of e.g. Baldwin, Francois and Portes 1997, Gasiorek, Smith and Venables 1997. The welfare implications of environmental action are ambiguous due to spillover effects (see Böhringer and Rutherford 2000, Böhringer and Löschel 2002). The spillover effects might harm the FSU and ROW.

Table 6 Marginal abatement costs (in USD per ton $\mathrm{CO}_{2}$ ) and welfare effects (in \%)

\begin{tabular}{lcccc}
\hline Region & \multicolumn{2}{c}{ Marginal abatement costs } & \multicolumn{2}{c}{ Welfare effects } \\
& NO_LIB & LIB & NO_LIB & LIB \\
\hline CEA & 0.19 & 0.19 & 0.44 & 1.05 \\
FSU & 0.00 & 0.00 & -0.05 & -0.01 \\
EUR & 44.34 & 44.91 & -0.35 & -0.30 \\
RAB & 56.36 & 56.41 & -0.68 & -0.69 \\
ROW & 0.00 & 0.00 & -0.07 & -0.10 \\
\hline
\end{tabular}

\section{Comparative advantage and trade patterns}

Carbon abatement policies have a direct impact on the overall comparative advantage and the international competitiveness of industries. The CEA countries possess a comparative advantage in the heavy industry, which has a long tradition in the transition economies due to the low cost of mostly subsidized energy. The strict domestic abatement policy implies the loss of the competitiveness in the EU energy intensive industry with negative implications on production and employment. Accordingly, energy intensive production rises in CEA and falls in EUR. With lower carbon prices under Annex-B trading and global trading the comparative advantage of the CEA energy intensive industries disappears and the effects on production effects are reversed. Trade liberalization deepens these detrimental effects of environmental policy (Table 7). Domestic environmental policy in all countries leads to a slight decrease in output of almost all sectors in the CEA with exception to the energy intensive goods and electricity production. This might be explained as a consequence of the increase in imports of the EU due to the increased competitiveness of energy intensive industries in CEA (Table 8). The cooperative environmental policy (i.e. Annex B and global carbon permit trading) leads to a substantial decrease in energy intensive production especially in the coal and surprisingly 
gas industry. Carbon leakage rates mimic the effects of carbon abatement policies on energy intensive production (Table 9). Carbon leakage is the relocation of the energy intensive industries or the increase of imports of energy intensive products. The calculations show leakage rates within the range found in the literature. Carbon trading lessens the magnitude of carbon leakage.

Table 7 Impacts of the environmental policies in the energy intensive sector (in \%)

\begin{tabular}{ccccccc}
\hline Region & \multicolumn{3}{c}{ NO-LIB } & \multicolumn{3}{c}{ LIB } \\
& DOMESTIC & ANNEX GLOBAL & DOMESTIC & ANNEX & GLOBAL \\
\hline CEA & 4.01 & -5.83 & -2.07 & 2.84 & -8.04 & -4.04 \\
EUR & -1.26 & 0.30 & 0.66 & -1.20 & 0.44 & 0.79 \\
\hline
\end{tabular}

Table 8 Energy intensive trade with trade liberalization between EU and CEEC (in \%)

\begin{tabular}{lcrrrrrrr}
\hline Region & \multicolumn{4}{c}{ NO-LIB } & \multicolumn{4}{c}{ LIB } \\
& \multicolumn{2}{c}{ DOMESTIC } & \multicolumn{2}{c}{ ANNEX } & \multicolumn{2}{c}{ DOMESTIC } & \multicolumn{2}{c}{ ANNEX } \\
& EUR & CEA & EUR & CEA & EUR & CEA & EUR & CEA \\
\hline CEA & -20.91 & & -32.46 & 5.93 & & -7.69 & & \\
FSU & -10.23 & 23.00 & -56.59 & -10.17 & 18.44 & 22.43 & -36.74 & -39.78 \\
EUR & & -2.06 & & -0.94 & & -1.36 & & 0.81 \\
RAB & -32.95 & -8.09 & -22.52 & 1.16 & -10.93 & -7.89 & 5.83 & 0.36 \\
ROW & -18.88 & 11.20 & -16.93 & 0.71 & 7.68 & 11.37 & 13.34 & 7.48 \\
\hline
\end{tabular}

Table 9 Carbon leakage (in \%)

\begin{tabular}{ccccc}
\hline Leakage rates & \multicolumn{2}{c}{ NO-LIB } & \multicolumn{2}{c}{ LIB } \\
& DOMESTIC & ANNEX & DOMESTIC & ANNEX \\
\hline 19.91 & 15.12 & 19.98 & 15.23 \\
\hline
\end{tabular}


ANNEX-B and GLOBAL: The impacts of the carbon emission permits trading.

In the trading scenarios the Annex-B countries are allowed to benefit from the flexible instruments introduced in the Kyoto protocol. In this scenario especially the degree of the recovery in Russia and particularly the Central European Associates is of importance, as they will become the largest suppliers of the emission permits on the world market. The flexibility of meeting the Kyoto targets allows the price of the permit to be lower then in the no trading case. The extending of the carbon allowance trading enables to exploit further efficiency gains from lower cost abatement possibilities in the rest of the world (Table 10). This lowers accordingly the negative welfare impacts in the EUR and RAB, who undertake the main abatement effort (Table 11). The decrease in welfare of CEA and FSU follows from the decrease of the carbon price. Further trade liberalization does not influence the marginal abatement costs, however contributes to an increase in welfare of the EU and CEA. The changes in the sectoral output as well as trade impacts arise as a response to the specific environmental policies since emission trading will have a direct impact on the relative prices of the products traded on world markets. These impacts will however be different between individual countries, depending on the composition and direction of their imports and exports.

Table 10 Marginal abatement costs in the trading scenarios with no trade liberalization between EU and CEEC (in USD per ton $\mathrm{CO}_{2}$ )

\begin{tabular}{lcccccccc}
\hline & \multicolumn{4}{c}{ NO-LIB } & \multicolumn{3}{c}{ LIB } \\
Region & ANNEX & GLOBAL & ANNEX & GLOBAL \\
& MAC & Welfare & MAC & Welfare & MAC & Welfare & MAC & Welfare \\
\hline CEA & 19.37 & 0.88 & 9.61 & 0.33 & 19.48 & 1.44 & 9.66 & 0.93 \\
FSU & 19.37 & 6.28 & 9.61 & 2.83 & 19.48 & 6.39 & 9.66 & 2.91 \\
EUR & 19.37 & -0.15 & 9.61 & -0.02 & 19.48 & -0.09 & 9.66 & -0.04 \\
RAB & 19.37 & -0.36 & 9.61 & -0.18 & 19.48 & -0.37 & 9.66 & -0.19 \\
ROW & 0.00 & -0.04 & 9.61 & -0.06 & 0.00 & -0.06 & 9.66 & -0.08 \\
\hline
\end{tabular}


Table 11 Carbon trade (in Mtons $\mathrm{CO}_{2}$ )

\begin{tabular}{lcrrr}
\hline & \multicolumn{2}{c}{ NO-LIB } & \multicolumn{2}{c}{ LIB } \\
Region & ANNEX & GLOBAL & ANNEX & GLOBAL \\
\hline CEA & 183.83 & 108.21 & 184.18 & 108.36 \\
FSU & 1298.05 & 1052.94 & 1298.99 & 1052.95 \\
EUR & -325.90 & -482.66 & -330.78 & -488.28 \\
RAB & -1155.96 & -1652.45 & -1152.37 & -1651.26 \\
ROW & - & 973.96 & - & 978.26 \\
\hline
\end{tabular}

\section{Conclusions and some remarks for further research}

This paper analyzes the impacts of different environmental policies in the process of the EU enlargement. Since the Europe agreements between the EU and the CEEC, a scheduled liberalization of trade flows has occurred. We have considered the same set of environmental policies under the current trade arrangements and under free trade between EU and CEEC. The calculations confirm other research, e.g. by Baldwin, Francois and Portes (1997) or Gasiorek, Smith and Venables (1997), showing that large gains are in stake for the CEECs while integration holds only modest efficiency gains for the EU member states. Integration shows very slight impacts on environmental policies and marginal abatement costs. The price of the carbon penalty is almost unchanged. However, integration mitigates to a large extent the welfare losses caused by environmental policy. Under domestic carbon abatement policies, the EU energy intensive industry lose competitiveness and accordingly, energy intensive production rises in CEA and falls in EUR. This comparative advantage disappears with lower carbon prices under Annex-B trading and global trading. Carbon leakage rates mimic the effects of carbon abatement policies on energy intensive production. As expected, emission trading provides substantial benefits mainly to the main seller of permits i.e. the former Soviet Union and the central and eastern European associates. Those regions also benefit from further trade liberalization. On the other hand the welfare losses of the EU under the trading regimes are very small. Trade liberalization even offsets part of it.

There are several issues constituting the need for further research and model improvement. Starting from the development of the suitable and detailed database covering 
disaggregated social accounting matrices for the associated countries. Detailed trade flows as well as information about remaining trade barriers (e.g. estimation of the non-tariff trade barriers) are necessary. The market structure in the economies in transition is far from perfect competition, thus several market imperfections in production, in the labor market etc. and short-time adjustments have to be considered. Important fiscal features of the EU, as the structural funds and common agricultural policy are still not incorporated. The extension of the model to capture other greenhouse gases especially $\mathrm{N}_{2} \mathrm{O}$ and $\mathrm{CH}_{4}$, resulting from agriculture, might be useful.

\section{References}

Armington P. S. (1969), A Theory of Demand for Products Distinguished by Place of Production, IMF Staff Papers 16, 159-178

Baldwin R., Francois J. and Portes R. (1997), The cost and benefits of eastern enlargement: the impact on the EU and central Europe, Economic policy, 4/1997

Baumert K., Petkova E., and Barbu D. (1999), Capacity for Climate Economies in Transition after Kyoto, The regional environmental center for Central and Eastern Europe, World Resources Institute

Bommer R. (1998), Economic integration and the environment, Cheltenham: Edward Elgar Publishing

Böhringer C., Rutherford T. F. (2000), Decomposing the Cost of Kyoto. A Global CGE Analysis of Multilateral Policy Impacts, ZEW Discussion Paper 00-11, Mannheim

Böhringer C., Löschel A. (2002), The economic impacts of carbon abatement strategies, in: C. Böhringer, M. Finus and C. Vogt (eds.), Controlling Global Warning, Cheltenham: Edward Elgar Publishing (forthcoming)

Breuss, F., Schebeck F. (1999), Costs and Benefits of EU's Eastern Enlargement for Austria, Austria Economic Quarterly, 4, 43-54

Cofala J., Jantzen J. de Haan B.J. (2000), Technical Report on Enlargement, RIVM

DOE (1998), Annual Energy Outlook, Energy Information Administration

EMF-16 Working Group (1999), Economic and Energy System Impacts of the Kyoto Protocol: Results from the Energy Modeling Forum Study, Stanford Energy Modeling Forum, Stanford University 
EC - European Commission (1997), Agenda 2000, Luxembourg

Europäische Kommission (2000), Agenda 2000: Stärkung und Erweiterung der Europäischen Union, Luxembourg

Francois J., McDonald B., and Nordström H., (1996) Liberalization and capital accumulation in the GTAP model, GTAP Technical Paper No.7

Francois J., Roland-Holst D. (1997), Scale economies and imperfect competition, in: J. Francois and K. Reinert (eds), Applied methods for trade policy analysis, Cambridge University Press

Francois J. (1997), Scale economies, imperfect competition and the eastern expansion of the EU, Research report 12 / 9713, Europa Institut

Frandsen S. and H. Jensen (2001), Economic Impacts of the Enlargement of the European Union, Analysing the importance of direct payments, Danish Institute of Agricultural and Fisheries Economics (SJFI), Paper presented at the GTAP conference 2001

Gasiorek M., Smith A. and Venables A.J. (1997), Modelling the Effect of Central and East European Trade on the European Community, European Economy, 6, 521-538

Goulder L.H. (1995), Environmental taxation and the double dividend: A reader's guide, International Tax and Public Finance, 2, 155-82

Grubb M. (2000), Economic dimensions of technological and global responses to the Kyoto protocol, Journal of Economic Studies, 27 (1/2), 111-125

Helpman E., Krugman P. R. (1985), Market Structure and Foreign Trade, Cambridge, MA

Homeyer von I. and A. Carius (2000), Die Osterweiterung der Europäischen Union als Herausforderung für die Umweltpolitik., Zeitschrift für Umweltpolitik und Umweltrecht, 3/2000, 337-368

IEA International energy agency (1996), Energy prices and taxes, Energy balances of OECD and non-OECD countries, Paris, IEA Publications

IPCC (2001), Climate change 2001: Mitigation, Contribution of Working Group III to the Third Assessment Report of the Intergovernmental Panel on Climate Change, Cambridge University Press

Kaderjak P., Powell J. (1997), Economics for environmental policy in transition economies, Cheltenham: Edward Elgar Publishing

Keuschnigg C., Kohler W. (1999), Eastern enlargement to the EU: Economic costs and benefits for the EU present member states, Final report, Saarbrücken/Linz 
Keuschnigg C., Keuschnigg M., Kohler W. (2000), The German perspective on eastern EU enlargement, Economic series 0007, Universität des Saarlandes, Saarbrücken.

Klarer J., Francis P. and McNicholas J. (1999), Improving Environment and Economy: The Potential of Economic Incentives for Environmental Improvements and Sustainable Development in Countries with Economies in Transition, REC, Szetendre

Klarer J., McNicholas J., Knaus E-M. (1999), Sourcebook on economic instruments for environmental policy, Central and Eastern Europe, REC, Szentendre

Klarer J., Moldan B. (1997), The environmental challenge for Central European economies in transition, London: John Wiley

Lipsey R. (1960), The theory of customs unions: A general equilibrium analysis, LSE research monographs

Lubinski M. (1996), Transformation - energy - environment country compilation for Poland, in: F. Müller and S. Ott (eds.), Energy and the environment in Central and Eastern Europe, Stiftung Wissenschaft und Politik

Markusen J. (1981), Trade and gains from trade with imperfect competition, Journal of international economics, 11, 531-551

Markusen J. et al. (1995), International trade , McGraw-Hill

McDougall R.A., Elbehri A. and Truong T.P. (1998), Global trade, Assistance and Protection:

The GTAP 4 Data Base, Center for Global Trade Analysis, Purdue University, West Lafayette.

Michaelowa A., Betz R., (2000), Implications of EU enlargement on the EU greenhouse gas "bubble" and internal burden sharing., HWWA Discussion paper 92

Nordström H., Vaughan S. (1999), Trade and environment, Geneva : WTO (Special studies 4)

Piazolo D. (2000), Eastern Europe between Transition and Accession: An Analysis of Reform Requirements, Kiel Institute of World Economics, Working Paper 991

REC (1993), Environmental Action Plan for CEEC 1993, Budapest Szentendre

REC (1994), Strategic environmental issues in Central and Eastern Europe, Regional report,

Volume 1, 2

Rutherford T. (1995), Carbon Dioxide Emission Restrictions in the Global Economy: Leakage, Competitiveness and the Implications for Policy Design, American Council for Capital Formation, Washington D.C.

Second national communications Slovakia, Bulgaria, Czech Republic, Hungary, Poland, Romania, www.ipcc.ch 
Sejak J. (1996), The Czech Republic: Combining market economy and environmental protection, in: F. Müller and S. Ott (eds.), Energy and the environment in Central and Eastern Europe, Stiftung Wissenschaft und Politik

Siebert H. (1991), The New Economic Landscape in Europe, Oxford: Basil Blackwell.

Toman M. (1994), Using economic incentives to reduce air pollution emissions in Central and eastern Europe: The case of Poland, in: M. Toman (ed.) Pollution abatement strategies in Central and Eastern Europe, Resources for the future, Washington D.C.

UNFCCC (1997), United Nations Framework Convention on Climate Change, Kyoto Protocol to the United Nations Framework Convention on Climate Change, FCCC/CP/L.7/Add.1, Kyoto

Weyant J. (ed.) (1999), The Costs of the Kyoto Protocol: A Multi-Model Evaluation, The Energy Journal, Special Issue

World Bank (1999), Czech Republic Toward EU Accession, Summary report, Washington D.C.

World Bank (1991), Czechoslovakia, Transition to a market economy, Summary report, Washington D.C. 


\section{Appendix}

\section{Algebraic model summary}

Two classes of conditions characterize the competitive equilibrium: zero profit conditions and market clearance conditions. The former class determines activity levels and the latter determine price levels. In our algebraic exposition, the notation $\Pi_{i}^{z}$ is used to denote the profit function of sector $i$ where $z$ is the name assigned to the associated production activity. Differentiating the profit function with respect to input and output prices provides compensated demand and supply coefficients (Shephard's lemma), which appear subsequently in the market clearance conditions. Table A1 explains the notations for variables and parameters. Table A2 gives an overview of key elasticities and parameter specifications For the sake of transparency, we do not write down the explicit functional forms but instead use the acronyms CET (constant elasticity of transformation), CES (constant elasticity of substitution), CD (Cobb-Douglas) and LT (Leontief) to indicate the class of functional form in place.

\section{Zero profit conditions}

Aggregate output: $\quad \Pi_{i}^{Y}=P_{i}-C E S\left[P R_{i}, L T\left(P A_{j, j \in I}^{\mathrm{Y}}, P K_{i}, P L\right)\right]=0 \quad \forall i \in F$

$$
\Pi_{i}^{Y}=P_{i}-L T\left[P A_{n, n \in N}^{Y}, P A_{C R U}^{Y}, C E S\left(P L, C E S\left(P K_{i}, P E_{i}\right)\right)\right]=0 \quad \forall i \in V
$$

Energy aggregate: $\Pi_{i}^{E}=P E_{i}-C E S\left[P A_{E L E}^{Y}, C E S\left(P A_{C O L}^{Y}, C E S\left(P A_{G A S}^{Y}, P A_{O L L}^{Y}\right)\right)\right]=0 \quad \forall i \in V$

Armington aggregate: $\Pi_{d i}^{A}=P A_{i}^{d}-C E S\left(P_{i}, P M_{i}\right)-P^{C O 2} a_{d i}^{C O 2}=0$

Aggregate imports: $\quad \Pi_{i}^{M, r}=P M_{i}^{r}-\operatorname{CES}\left(P_{i}^{s}, P F X\right)=0$

Investment:

$$
\Pi^{I N V}=P I N V-L T\left(P A_{i, i \in I}^{Y}\right)
$$

Public demand: $\quad \Pi^{Z}=P Z-C D\left(P A_{n, n \in N}^{Z}, C E S\left(P A_{e, e \in E}^{Z}\right)\right)=0$

Final demand: $\quad \Pi^{C}=P C-C E S\left(C D\left(P A_{e, e \in E}^{C}\right), C D\left(P A_{n, n \in N}^{C}\right)\right)=0$ 
Market Clearance Conditions

Labor:

$$
\bar{L}=\sum_{i} Y_{i} \frac{\partial \prod_{i}^{Y}}{\partial P L}
$$

Capital:

$$
\bar{K}=\sum_{i} Y_{i} \frac{\partial \Pi_{i}^{Y}}{\partial P K}
$$

Natural resources:

$$
\bar{Q}_{f}=Y_{f} \frac{\partial \Pi_{f}^{Y}}{\partial P R_{f}}
$$

Domestic output:

$$
Y_{i} \frac{\partial \prod_{i}^{Y}}{\partial P_{i}}=\sum_{d} A_{i}^{d} \frac{\partial \Pi_{d i}^{A}}{\partial P_{i}}
$$

Energy aggregate: $\quad E_{i}=Y_{i} \frac{\partial \Pi_{i}^{Y}}{\partial P E_{i}}$

Import aggregate:

$$
M_{i}=\sum_{d} A_{i}^{d} \frac{\partial \prod_{d i}^{A}}{\partial P M_{i}}
$$

Armington aggregate: $\quad A_{i}^{Y}=\sum_{j} Y_{j} \frac{\partial \Pi_{j}^{Y}}{\partial P A_{i}^{Y}}+I N V \frac{\partial \Pi^{I N V}}{\partial P A_{i}^{I N V}}$

$$
\begin{aligned}
& A_{i}^{C}=C \frac{\partial \Pi^{C}}{\partial P A_{i}^{C}} \\
& A_{i}^{Z}=Z \frac{\partial \Pi^{Z}}{\partial P A_{i}^{Z}}
\end{aligned}
$$

Private demand: $\quad P C \cdot C=P L \cdot \bar{L}+P K \cdot \bar{K}+\sum_{f} P Q_{f} \cdot \bar{Q}_{f}-P I N V \cdot \overline{I N V}-P C \cdot \bar{B}^{r}$

Government consumption: $P Z \cdot Z=P^{\mathrm{CO} 2} \cdot \overline{\mathrm{CO} 2}+$ other taxes

Government output:

$$
\bar{Z}=Z
$$

Investment:

$$
\overline{I N V}=I N V
$$

Carbon emission constraint: $\quad \overline{\mathrm{CO} 2}=\sum_{d} \sum_{i} A_{i}^{d} a_{d i}^{\mathrm{CO} 2}$ 
Table A1 Sets, activity and price variables, endowments

Sets:

$I, i, j \quad$ Sectors and goods (13 commodities)

$E, e \quad$ Energy goods (COL, CRU, OIL, GAS and ELE)

$N, n \quad$ Non energy goods

$F, f \quad$ Fossil fuels (COL, CRU, GAS)

$V, v \quad$ Non fossil fuels

$r, s \quad$ Regions

$d \quad$ Demand categories: $\mathrm{Y}=$ industry, $\mathrm{C}=$ household, $\mathrm{Z}=$ government

Activity variables:
$Y_{i} \quad$ Aggregate production
$E_{i} \quad$ Aggregate energy input
$A_{i}^{d} \quad$ Armington aggregate
$M_{i} \quad$ Import aggregate
C Private consumption
Z Government consumption

Price variables:

$P_{i} \quad$ Output price

$P E_{\mathrm{i}} \quad$ Price of aggregate energy

$P A_{i}^{d} \quad$ Price of Armington aggregate

$P M_{i} \quad$ Price of import aggregate

$P U \quad$ Utility price index

$P C \quad$ Price of aggregate household consumption

$P Z \quad$ Price of government consumption

$P L \quad$ Wage rate

$P K \quad$ Price of capital services

$P Q_{f} \quad$ Rent from natural resource

PINV Price of investment demand

$P^{C O 2} \quad$ Price of carbon permit 
Endowments:

$\bar{L} \quad$ Aggregate labor endowment

$\bar{K} \quad$ Aggregate capital endowment

$\bar{Q}_{f} \quad$ Endowment of natural resource

$\bar{B}^{r} \quad$ Balance of payment surplus

$\overline{\mathrm{CO} 2} \quad$ Endowment with carbon emission rights

Other parameters:

$a_{i}^{C O 2} \quad$ Carbon coefficient per unit

Table A2 Overview of key elasticities and parameter specifications

Substitution elasticities in non-fossil fuel production

Capital-labor-energy vs. intermediates 0

Capital-energy vs. labor $\quad 0.6$

$\begin{array}{ll}\text { Capital vs. energy } & 0.8\end{array}$

$\begin{array}{ll}\text { Electricity vs. primary energy inputs } & 0.1\end{array}$

Gas-oil vs. coal $\quad 0.5$

Gas vs. oil 2

Substituion elasticities in final demand

$\begin{array}{ll}\text { Energy goods vs. non-energy goods } & 0.5\end{array}$

Non-energy goods vs. non-energy goods 1

Energy goods vs. energy goods 1

Substitution elasticities in government demand

Fossil fuels vs. non-fossil fuels 1

$\begin{array}{ll}\text { Fossil fuels vs. fossil fuels } & 0.3\end{array}$

Elasticities in international trade (Armington)

Substitution elasticity between imports vs. domestic inputs 4

Other Parameters

$\begin{array}{ll}\text { Supply elasticity for crued oil } & 1\end{array}$

Supply elasticity for gas 1

Supply elasticity for coal $\quad 0.5$ 